\title{
O DIREITO FUNDAMENTAL DA LIBERDADE DE IMPRENSA COMO MECANISMO DE CONSTRUÇÃO DO DESENVOLVIMENTO SUSTENTÁVEL
}

Gabriela Soldano Garcez

Advogada e Jornalista diplomada. Pós-graduada em Direito Processual Civil e Direito Processual do Trabalho, pela Universidade Católica de Santos. Mestre em Direito Ambiental (bolsista CAPES) e Doutoranda em Direito Ambiental Internacional (bolsista CAPES), ambas pela Universidade Católica de Santos. Conciliadora capacitada pela Escola Paulista da Magistratura.

Constança Gonzaga Junqueira de Mesquita

Sócia da "Da Costa Fernandes Advogados". Desembargadora aposentada do Tribunal de Justiça do Estado de São Paulo. Doutora em Direito Civil, pela Universidade de São Paulo.

\section{Resumo}

É inegável, na atual sociedade globalizada e de informação, o papel fundamental dos veículos de comunicação de massa para a formação da opinião pública sobre os mais diversos temas. Daí, a importância da liberdade de imprensa, um dos pilares na edificação de um real Estado Democrático de Direito por exercer funçóes sociopolítica e cultural manifestas, na medida em que, através da concessão de informação de qualidade, tem o potencial de contribuir para a obtenção e execução de direitos fundamentais, tais como o meio ambiente ecologicamente equilibrado, tendo em vista que contribui para a formação da opinião pública em prol do desenvolvimento sustentável. Nesta linha de raciocínio, o presente trabalho visa, primeiramente, analisar o direito à liberdade de imprensa, indicando de que modo a informação tornou-se condição essencial para a democracia. Em seguida, aborda a utilização da comunicação a favor do meio ambiente, ponderando sobre de que forma a atuação consciente dos veículos de comunicaçáo de massa pode contribuir para o avanço no caminho do desenvolvimento sustentável. Por fim, avalia a promoção da cidadania por meio da informação de qualidade, no contexto atual de governança global e globalização.

\section{Palavras-chave}

Desenvolvimento Sustentável; Comunicação Social; Informação; Participação; Liberdade de Imprensa; Veículos de comunicação de massa; Democracia. 


\section{Abstract}

It is undeniable, in today's global and information society, the fundamental role of the mass media for the formation of public opinion on various topics. Hence the importance of press freedom, one of the pillars in building a real democratic state, for exercise social, political and cultural functions, in that, by granting quality information, has the potential to contribute to the adoption and enforcement of fundamental rights, such as an ecologically balanced environment, considering that contributes to the formation of public opinion in favor of sustainable development. In this line of reasoning, this paper aims, at first, to analyze the right to press freedom, indicating how the information has become an essential condition for democracy. Then, it addresses the use of communication in favor of the environment, pondering how the conscious action of the mass communication media can contribute to the progress towards sustainable development. Finally, this paper evaluates the promotion of citizenship through quality information, in the current context of globalization and global governance.

\section{Key words}

Sustainable Development; Media; information; participation; Freedom of the Press; Mass communication vehicles; Democracy.

\section{Introdução}

A imprensa serve ao público através da informação.

A concessão de informação de qualidade permite repassar valores e questionamentos, contribuindo para cimentar a relação da comunicação e a grande massa receptora destas informações (a população), bem como destacar a influência que exerce sobre a formação da opiniáo pública, inclusive no que se refere a proteção e defesa do meio ambiente, ao colaborar para a construção de um futuro baseado no desenvolvimento sustentável.

Neste contexto, diante da importância dos veículos de comunicação de massa na atual sociedade da informaçáo, o presente trabalho visa, primeiramente, analisar o direito à liberdade de imprensa, indicando de que modo a informação tornou-se condição essencial para o Estado Democrático de Direito.

Em seguida, aborda a comunicaçáo a prol do meio ambiente, ponderando sobre de que forma a atuação consciente dos veículos de comunicação pode contribuir para o desenvolvimento sustentável.

Por fim, avalia a promoção da cidadania por meio da informação de qualidade, na medida em que fornece subsídios para a participação qualificada da população, que, po- 
derá a partir daí, participar dos debates sobre a matéria, no contexto atual de governança global e globalização.

\section{Do Direito Humano Fundamental a Liberdade de Imprensa - A Informação como Condição Essencial para a Democracia}

Onde há vida há comunicação.

Os sistemas de comunicação deram início (ou ao menos contribuíram) aos avanços da civilização humana, uma vez que a partir do domínio dos mais variados meios de comunicação de massa iniciou-se as mudanças críticas na evolução humana.

Foi a crescente capacidade para comunicar-se cabal e perfeitamente que levou ao desenvolvimento crescente de complexa tecnologia e a mitos, lendas, explicações, lógica, hábitos, e às regras complexas para o comportamento que possibilitaram a civilização (DEFLEUR, 1993, p. 22).

Sempre que há mudança na comunicação, há evolução. Por isso, a história humana pode ser contada a partir do desenvolvimento da comunicação.

A primeira das grandes Eras da comunicação foi a Era dos Símbolos e Sinais, que surgiu na era pré-hominídea, muito antes do homem caminhar ereto. Nesta época, a comunicação dava-se através de respostas instintivas, por meio de ruídos e movimentos corpóreos, sendo certo que não havia quase nenhum comportamento adquirido através da comunicação com outros seres. Com o passar dos anos, os sinais foram ficando cada vez mais elaborados a partir do aprendizado adquirido observando os demais. Porém, ainda não havia qualquer sinal de linguagem falada.

As primeiras formas humanas se comunicavam através de sons primitivos, gestos, sinais, expressões faciais e posturas, que adotavam em relação aos demais. Os outros tinham de interpretar. Por esta razão, a comunicação entre os seres não era rápida, mas sim restrita ao que o outro podia deduzir naquele determinado momento.

Dessa forma, os meios de comunicação eram demasiadamente complicados e ineficientes. Entretanto, estes meios permitiam aos seres primitivos pensar e inovar. Este é um dos efeitos mais remotos da comunicação.

Com o aparecimento de uma das formas do Homo Sapiens, o Cro-Magnon, os seres humanos entraram na Era da Fala e da Linguagem. É neste período que surgem as táo famosas pinturas rupestres. Tais pinturas foram as precursoras da escrita e, consequentemente, as primeiras formas de armazenamento de informaçóes.

Nesta época, a linguagem falada é a única conhecida pelos indivíduos. Foi com a linguagem que o ser humano pode aprender, lembrar e transmitir qualquer tipo de mensagem. A criação da civilização teria sido impossível sem a linguagem. 
Posteriormente, houve a transição para a Era da Escrita, quando as letras passaram a significar sons.

A interpretação de determinada imagem gráfica passou a ser uma só para todos os indivíduos, o que facilitou a comunicação. A distância e o tempo não eram mais nenhum empecilho, mas sim a forma de transportar a escrita de um local para outro.

Para facilitar o transporte, os egípcios criaram o papel, utilizando o papiro. Esse foi o primeiro veículo de comunicação da História. Posteriormente, em 1455, foi produzido por Gutenberg, na cidade alemã denominada Mainz, o primeiro livro por uma prensa com tipos móveis fundidos em metal. Dava-se início a Era da Imprensa.

Antes da impressão, os livros eram de difícil acesso, uma vez que tinham de ser reproduzidos a mão e, por esta razáo, eram extremamente raros e caros. Entretanto, com a invenção da prensa milhares de cópias podiam ser realizadas sem qualquer erro de grafia.

Já em 1621, surgiram os precursores dos jornais, os chamados Corantos, que traziam informaçôes sobre o estrangeiro. Infelizmente, não tinham publicação regular, pois eram regulados pelo governo de seus respectivos países de origem.

Com o tempo e aperfeiçoamento das informaçôes, surgiu o primeiro jornal. Com técnica rápida de impressão e baixo custo para a distribuição, o jornal ficou conhecido como "penny press", ou seja, "jornal do tostão" (porque custava apenas "um tostão"), em 1830, na cidade de Nova York. Assim, o primeiro jornal de massa chegou às ruas de Nova York em 1834, criado por Benjamin H. Day, com o nome de New York Sun, sobre notícias locais, histórias de interesse coletivo e sensacionalismo.

O telégrafo e até o navio a vapor contribuíram para a coleta das informaçóes e como meio de transporte para os jornais elaborados. A partir daí, o jornal de massa espalhou-se por todas as partes do mundo.

No Brasil, o primeiro jornal impresso surge em 1808: A Gazeta do Rio de Janeiro e, em 1822, o Correio Braziliense, sob direção de José Hipólito da Costa, em Londres.

Os "novos" veículos de massa (jornais, revista e livros) traziam mudanças na estrutura social e política, rompendo todas as barreiras até então existentes entre as pessoas nos mais diferentes lugares do mundo.

Há quatro fatores que tornam os novos veículos bem mais eficientes do que os processos de comunicação de qualquer sociedade anterior. Os novos meios eram mais eficazes, disse ele, em termos de: 1) expressividade, por incluírem uma ampla gama de ideias e sentimentos; 2) permanência do registro, ou a superaçấo do passar do tempo; 3) presteza, ou a superação do espaço; 4) difusão, ou acesso a todas as espécies de homens (DEFLEUR, 1993, p. 40). 
Assim, com o acesso de todos aos jornais e com o aumento das mídias elétricas (como o telefone) surge a Era da Comunicação de Massa, que sofreu um grande impulso no século XX, com a invenção da televisão (meio de comunicação de massa por excelência, pois é o que possui atualmente maior alcance), filme e rádio, que contribuem para a modificação da sociedade até hoje.

Recentemente, ingressamos na Era dos Computadores, com o advento da World Wide Web, o que contribuiu fundamentalmente para a modificação dos veículos de massa que conhecemos hoje.

Tais Eras foram os passos iniciais da História da Imprensa, que, atualmente, engloba qualquer meio de comunicação de massa, ou seja, os meios que passam informaçóes diversas para a população em geral.

Ainda em 1776, a Bill of Rights, do Estado de Virgínia, nos Estados Unidos (que inspirou a Declaração dos Direitos do Homem, criada em 1789), ditava que: "A livre comunicação do pensamento e da opinião é um dos direitos mais preciosos do homem; todo cidadão pode, por conseguinte, falar, escrever, imprimir livremente, respondendo, porém, pelos abusos desta liberdade nos casos determinados em lei" (MIRANDA, 1994, p. 41).

Tal preceito encontra-se na Constituição Federal, de 1988, no artigo 5º, incisos IX e XIV: "é livre a expressão da atividade intelectual, artística, cientifica e de comunicação, independentemente de censura ou licença", e, "é assegurado a todos o acesso à informação e resguardado o sigilo da fonte, quando necessário ao exercício profissional'.

Há respaldo, ainda, no artigo 220, da mesma Constituição Federal:

A manifestação do pensamento, a criação, a expressão e a informação, sob qualquer forma, processo ou veículo não sofrerão qualquer restrição, observado o disposto nesta Constituição.

$\$ 1^{\circ}$ - Nenhuma lei conterá dispositivo que possa constituir embaraço à plena liberdade de informaçáo jornalística em qualquer veículo de comunicaçấo social, observado o disposto no art. 5º, IV, V, X, XIII e XIV.

$\$ 2^{\circ}$ - É vedada toda e qualquer censura de natureza política, ideológica e artística.

A conjunção de tais artigos leva ao entendimento de que, o direito à liberdade de imprensa configura um direito fundamental de primeira dimensão, na medida em que constitui uma liberdade pública, devendo ser respeitado pelo Estado, por garantir dignidade e condição de vida minimamente adequadas, proibindo os excessos do Estado, além de "dar melhores condiçóes no desenvolvimento da personalidade humana no contexto social" (GUERRA, 2004, p. 37).

Percebe-se que, falar do direito a liberdade de imprensa é referir-se ao direito à informação, uma vez que os veículos de comunicação, além de exercerem o direito a liber- 
dade de imprensa, garantem à "massa" o direito de informar e serem informados, pois a imprensa é, na atualidade, uma das poucas formas da população ter contato com os acontecimentos no Brasil e no mundo, sendo, portanto, "o pulmão através do qual o povo respira" (MIRANDA, 1994, p. 65).

O direito de informação (...) integra três níveis: o direito 'de informar', o direito 'de se informar' e o direito 'de ser informado'. O primeiro consiste, desde logo, na liberdade de transmitir ou comunicar informaçóes a outrem, de as difundir sem impedimentos, mas pode também revestir uma forma positiva, enquanto direito a informar, ou seja, direito a meios para informar. $\mathrm{O}$ direito de se informar consiste designadamente na liberdade de recolha de informação, de procura de fontes de informação, isto é, no direito de não ser impedido de se informar. Finalmente, o direito a ser informado é a versão positiva do direito de se informar, consistindo num direito a ser mantido adequadamente e verdadeiramente informado pelos meios de comunicação e pelos poderes públicos (...) (BASTOS; MARTINS, 1988, p. 81).

É, portanto, a comunicação realizada em série, com o objetivo de atingir a maior quantidade de indivíduos possível: a "massa”, ou seja, todas as pessoas que estão submetidas aos meios de comunicação (dependentes e fascinados) e, que a eles fazem referência.

É certo que, nos primórdios de sua vulgarização, a palavra imprensa englobava num mesmo conceito todos os produtos das artes gráficas, das reproduçôes por imagens e por processos mecânicos e químicos envolvendo livros, gravuras, jornais e impressos em geral, hodiernamente em virtude de seu grande desenvolvimento, essas mesmas artes se subdividiram, esgalhando-se em planos distintos, firmando cada qual uma nova especialidade, não sendo mais possível jungir a imprensa ao conceito dos velhos tempos (GODOY, 2001, p. 59).

Assim, o direito a informação, antes entendido apenas como um direito individual, ganha nuances, na realidade, de direito coletivo, "posto que abriga interesses particulares, coletivos e gerais" (SILVA, 1989, p. 230).

O direito de informar, como aspecto da liberdade de manifestação do pensamento, revela-se um direito individual, mas já contaminado de sentido coletivo, em virtude das transformações dos meios de comunicação, de sorte que a caracterização mais moderna do direito de comunicação, que especialmente se concretiza pelos meios de comunicaçáo social ou de massa, envolve a transmutação do antigo direito de imprensa e de manifestação do pensamento, por esses direito, em direitos de feição coletiva (GODOY, 2001, p. 59).

No âmbito internacional, o direito ao acesso a informação é garantido pelo Princípio 11, da Declaração de Direitos do Homem e do Cidadão, de 1789: 
A livre comunicação das ideias e das opinióes é um dos mais preciosos direitos do homem. Todo cidadáo pode, portanto, falar, escrever, imprimir livremente, respondendo, todavia, pelos abusos desta liberdade nos termos previstos na lei.

Ademais, há previsão no Princípio 19, da Declaração Universal dos Direitos Humanos de 1948:

Todos têm direito à liberdade de opinião e expressão; esse direito inclui a liberdade de expressar opinióes sem interferência e de buscar, receber e transmitir informaçóes e ideias por quaisquer meios e sem limitaçóes de fronteiras.

Há, ainda, disposição sobre a matéria no artigo 13, da Convenção Americana de Direitos Humanos, mais conhecida como Pacto de São José da Costa Rica, de 1969:

1. Toda pessoa tem o direito à liberdade de pensamento e de expressão. Esse direito inclui a liberdade de procurar, receber e difundir informaçóes e ideias de qualquer natureza, sem consideraçóes de fronteiras, verbalmente ou por escrito, ou em forma impressa ou artística, ou por qualquer meio de sua escolha.

2. O exercício do direito previsto no inciso precedente náo pode estar sujeito à censura prévia, mas a responsabilidades ulteriores, que devem ser expressamente previstas em lei e que se façam necessárias para assegurar:

a) o respeito dos direitos e da reputação das demais pessoas;

b) a proteção da segurança nacional, da ordem pública, ou da saúde ou da moral públicas.

3. Não se pode restringir o direito de expressão por vias e meios indiretos, tais como o abuso de controles oficiais ou particulares de papel de imprensa, de frequências radioelétricas ou de equipamentos e aparelhos usados na difusão de informação, nem por quaisquer outros meios destinados a obstar a comunicação e a circulação de ideias e opinióes.

A Constituição Federal de 1988 traz o princípio da informação no artigo 5º inciso XXXIII:

Todos têm direito a receber dos órgãos públicos informações de seu interesse particular, ou de interesse coletivo ou geral, que serão prestadas no prazo da lei, sob pena de responsabilidade, ressalvadas aquelas cujo sigilo seja imprescindível à segurança da sociedade e do Estado.

Por informação entende-se, segundo o artigo $4^{\circ}$, inciso I, da Lei no . 12.527/11, todos os "dados, processados ou não, que podem ser utilizados para produção e transmissão de conhecimento, contidos em qualquer meio, suporte ou formato". 
É fonte de conhecimento, tendo em vista que, no momento em que se informa, faz-se um registro daquilo que já existe ou que está em vias de existir, oferecendo a possibilidade de uma escolha fundamentada.

"Aquele que detém a informação coloca-se, inegavelmente, numa posição de vantagem aos demais" (RODRIGUES, 2002, p. 255), pois a partir deste conhecimento, a população pode ter voz ativa em debates, pois terá condiçóes de compreender e orientar as discussões, influindo nos acontecimentos.

Isso ocorre, porque, conhecimento é o "conjunto de declaraçôes organizadas sobre fatos ou ideias, apresentando um julgamento ponderado ou resultado experimental, que é transmitido a outros por intermédio de algum meio de comunicação, de forma sistematizada" (CASTELLS, 1993, p. 2003).

A informação torna-se, neste sentido, base e fundamento para a tomada de qualquer decisão, pois é condição para a análise dos fatos de forma segura.

O progresso tecnológico transformou a informação em um bem jurídico capaz não só de satisfazer a necessidade de saber, como também de influir decisivamente no seu uso. Proteger a capacidade de reflexão é o que se propóe o direito de informaçấo (CARVALHO, 2003, p. 209/2010).

Com isso, a informação e, consequentemente, os veículos de comunicação têm função essencial para a sustentação da democracia, na medida em que fornecem meios suficientes e adequados para que cada cidadáo tenha a habilidade e a capacidade de participar da vida pública, ao propiciar a formação de opinião, criando a possibilidade da chamada "democracia deliberativa" (THOMPSON, 2001, p. 220), onde a decisão será baseada num processo de deliberaçáo geral, que parte do pressuposto de que o indivíduo deve receber a necessária informação para a avaliação de diferentes pontos de vista, para, somente então, formar a sua opinião sobre o assunto, influindo no resultado final.

Por democracia deliberativa, entendo a concepção de democracia que trata todos os indivíduos como agentes autônomos, capazes de formar juízos razoáveis através da assimilação de informaçôes e diferentes pontos de vistas, e que institucionaliza uma variedade de mecanismos para incorporar os juízos individuais num processo coletivo de tomada de decisão. O processo de deliberação é necessariamente aberto. Quanto mais informação estiver disponível e mais os indivíduos poderem considerar os argumentos e reivindicaçôes dos outros, tanto mais poderáo gradualmente modificar seus pontos de vista, formar juízos de valor (THOMPSON, 2001, p. 220/221).

O efeito desta ideia, em relação aos veículos de comunicação de massa, é que estes sáo os responsáveis mediatos por formar os juízos de valor nos indivíduos sobre assuntos 
de seus interesses, podendo, inclusive, articular opinióes daqueles que seriam marginalizados ou excluídos de certa visibilidade pública e política.

Quanto mais os indivíduos forem capazes de participar na deliberação de questóes que lhes dizem respeito, e quanto mais os resultados de tais deliberações forem alimentados com procedimento que realizem a decisão, maiores serão as chances da democracia na organização política e social que modelam suas vidas (THOMPSON, 2001, p. 222).

Assim, a democracia só existe com a possibilidade de acesso a informação. " $O$ desinformado é um mutilado cívico" (MACHADO, 2006, p. 48).

\section{A Comunicação em Prol do Meio Ambiente - A Construção do Desen- volvimento Sustentável por Meio da Atuação Consciente dos Veículos de Comunicação de Massa}

Diante da relação intrínseca entre informação e democracia, percebe-se o compromisso dos veículos de comunicação para o exercício da liberdade de imprensa, pois, sob o pretexto de informar os fatos ocorridos, a mídia náo pode violar direitos, tais como a intimidade, privacidade e honra.

Sempre que houver excesso no direito de informar, seja este excesso culposo ou doloso, caracteriza-se o abuso. "Quer na exposição das ideias ou enunciação do pensamento, quer na maneira de buscar as fontes de informação, não pode o interessado transcender os lindes que a lei impóe, sem incursionar na área delituosa" (MIRANDA, 1994, p. 129).

Todo cidadão que for atingido, considerando-se ofendido diante de uma matéria vinculada por meio de um determinado veículo de comunicação de massa, pode (e deve) repelir pelos meios legais toda a ofensa sofrida.

"A imprensa é livre para a divulgação de informaçóes, fatos, notícias, crônicas, críticas etc., não para divulgar ofensas, deturpar a verdade, pregar a sedição, fazer a apologia a crimes e servir de veículo a fins extorsionários" (MIRANDA, 1994, p. 70).

Entretanto, não se pode confundir verdade com ofensa e, mesmo que o fato seja verdadeiro, não se pode exagerar ao veiculá-lo, tornando a notícia tendenciosa (difundida para atingir fim diverso daquele inicialmente pretendido).

"Já que as noticias são o material que as pessoas usam para aprender e pensar sobre o mundo além de seus próprios mundinhos, o mais importante é que a informação seja boa e confiável' (KOVACH; ROSENSTIEL, 2003, p. 61).

Estas restriçóes são necessárias para a manutenção da paz social, tendo em vista a influência que pode exercer sobre coletividade, por ser uma das poucas formas da populaçáo 
ter contato com os acontecimentos no Brasil e no mundo, e, por isso, deve ter limites a serem seguidos.

Assim, a mídia de forma geral tem grande papel na opinião da população, uma vez que estes veículos produzem os mais variados tipos de conteúdo, tornando-se os meios de formação da opiniáo pública, pois entregam ao público os ingredientes necessários para formar sua opiniāo, exercendo controle social.

"Opinião pública é o julgamento formado e levado em consideração por aqueles que constituem o público e diz respeito a negócios públicos" (BAHIA, 1964, p. 59).

A opinião pública nada mais é, portanto, do que o julgamento que o público faz de determinadas notícias vinculadas pelos meios de comunicação. Daí, a responsabilidade e a obrigação de diligenciar para que as notícias tenham a característica primordial da veracidade, transparecendo a atuaçáo consciente dos meios de comunicaçáo, conforme o que determina os princípios descritos no artigo 221, da Constituição Federal de 1988, que faz parte do Capítulo sobre a "Comunicação Social".

Entre tais princípios, vale destacar os incisos I e IV, que descrevem, respectivamente, que a produção e programação devem dar "preferência a finalidades educativas, artísticas, culturais e informativas", bem como respeitar "os valores éticos e sociais da pessoa e da familia".

Disso extrai-se que o jornalismo deve ter responsabilidade quanto as informaçóes que concede à sociedade. Responsabilidade que se infere inclusive nas matérias referentes a temática ambiental.

A comunicação social deve estar voltada à proteção do meio ambiente ecologicamente equilibrado, visando a manutenção da qualidade de vida das presentes e futuras gerações, bem como privilegiando o desenvolvimento sustentável.

Esse preceito constitucional é de extrema importância para garantir à coletividade os meios de ação diante de atividades de risco. De fato, atitudes preventivas e corretivas somente poderão ser tomadas se as informaçóes ambientais, geralmente concentradas em órgãos especializados, forem divulgadas junto à população (CODONHO, 2014, p. 110).

A comunicação é, atualmente, o viés capaz de enriquecer o caminho para um desenvolvimento baseado no conceito de sustentabilidade, proposto pelos novos paradigmas socioambientais.

O estudo denominado "Nosso Futuro Comum", também conhecido como Relatório Brundtland (realizado entre 1983 e 1987 pela Comissão Mundial sobre Meio Ambiente e Desenvolvimento (CMMAD), criada pela Assembleia Geral da ONU), apresenta o conceito de "desenvolvimento sustentável", tendo por base uma proposta 
de estratégia ambiental de longo prazo, visando a cooperação entre os países pela preocupação ambiental.

[O desenvolvimento sustentável é] aquele que atende às necessidades (que são determinadas social e culturalmente) das geraçóes atuais sem comprometer a capacidade das futuras gerações terem suas próprias necessidades - utilizar recursos naturais sem comprometer sua produção, tirar proveito da Natureza sem devastá-la e buscar a melhoria da qualidade de vida à sociedade (COMISSÃO MUNDIAL SOBRE MEIO AMBIENTE E DESENVOLVIMENTO, 1991, p. 10).

Desenvolvimento sustentável é, segundo a Comissão Mundial,

um processo de transformação no qual a exploração dos recursos, a direção dos investimentos, a orientação do desenvolvimento tecnológico e a mudança institucional se harmonizam e reforçam o potencial presente e futuro, a fim de atender às necessidades e aspiraçóes humanas (COMISSÃO MUNDIAL SOBRE MEIO AMBIENTE E DESENVOLVIMENTO, 1991, p. 9).

Dentre os mecanismos eficazes para a associação e equilíbrio entre o desenvolvimento socioeconômico e o respeito aos valores ambientais (estrutura do tripé econômico, social e ambiental, formador do desenvolvimento sustentável, conforme artigo $4^{\circ}$, inciso I, da Lei no . 6.938/81, mais conhecida como Política Nacional do Meio Ambiente, ao afirmar que o desenvolvimento econômico-social deve ser compatível com a preservação da qualidade do meio ambiente e do equilíbrio ecológico, indicando assim os três pilares inseparáveis que compóe o desenvolvimento sustentável: econômico, ambiental e social), encontra-se a informação.

Assim, para que este "processo de transformação" (mencionado pela Comissão Mundial) possa alcançar o fim a que se destina, é necessário que a comunicação social esteja voltada para a mesma finalidade, para que a população possa (a partir da informação de qualidade) compreender as suas próprias necessidades primárias e as do outro, bem como as utilidades dos recursos existentes, ou seja, o objetivo da informação ambiental deve ser instruir toda a comunidade nos princípios de sustentabilidade, justiça social e ambiental, precaução e prevenção, entre outros, visando a melhoria da qualidade de vida.

"A comunicação constrói sentidos que implicam associar, relacionar e contextualizar considerando que a trama de interaçóes com o outro e com o meio reconfigura a realidade" (ARAUJO; ROSSI, 2008, p. 71).

Neste contexto, reconhece-se aos veículos de comunicação de massa "a força estimuladora de imaginários" (SILVA, 2001, p. 176), pois a atuação destes permite alimentar o conhecimento da população acerca do que é necessário para a construção de um futuro baseado no desenvolvimento sustentável, ampliando a discussão sobre o tema. 
É indispensável a relação do homem com o meio ambiente de forma consciente e racional, em que a sustentabilidade criará chances para a abertura do desconhecido, para um futuro apropriado e novo, invencível ao presente, em cujo processo de desenvolvimento participante todos deverâo se envolver (ARAUJO; ROSSI, 2008, p. 70).

\section{A Promoção da Cidadania por Meio da Informação de Qualidade, no Con- texto da Governança Global}

No atual contexto de governança global e processos intrínsecos de globalização, a importância da comunicação para o desenvolvimento sustentável deve ser reforçada, uma vez que tem o potencial de oferecer instrumentos para mudanças de pensamento em contextos muito mais abrangentes e, inclusive, geopolíticos.

A governança se tornou uma expressão comum, desde o início do século XXI, nas áreas das Ciências Humanas, Sociais Aplicadas e afins, como sendo imprescindível para os processos de desenvolvimento tanto econômico quanto social, além de solução para problemas comuns entre Estados e atores não estatais, tendo em vista que é

cada vez maior a preocupação em estabelecer formas e mecanismos de gestão compartilhada do poder, de maneira transparente, onde Estados, Organizações Internacionais, empresas multinacionais e organizações da sociedade civil possam ter papel relevante (GONÇALVES, 2014, p. 83).

A expressão "governança" assume caráter específico para designar a capacidade exigida de organizaçóes e governos para a gestão adequada do desenvolvimento sustentável, "adotando politicas sociais e ambientais mais rigorosas, e garantindo um papel mais ativo para cidadãos e agentes locais" (GONÇALVES, 2014, p. 84).

$\mathrm{O}$ atual conceito surgiu através da Comissão sobre Governança Global, criado pela Organização das Naçóes Unidas (ONU), em 1992, como sendo:

a totalidade das diversas maneiras pelas quais os indivíduos e instituiçôes, públicas e privadas, administram seus problemas comuns. É um processo contínuo pela qual é possível acomodar interesses conflitantes e realizar açôes cooperativas. Governança diz respeito não só a instituições e regimes formais autorizados a impor obediência, mas a acordos informais que atendam aos interesses das pessoas e instituições (COMISSÃO SOBRE GOVERNANÇA GLOBAL, 1996, p. 2).

$\mathrm{O}$ crescente interesse para o estabelecimento de formas de governança nas mais diferentes áreas do conhecimento decorre da globalização, que pode ser entendida como o processo de integração do que acontece no mundo com características de instantaneidade e velocidade, além de possuir caráter polissêmico e multifacetado, uma vez que abrange 
mais de uma área, como, por exemplo: cultural, política, jurídica, econômica, entre outras, de modo complexo (SANTOS, 2005, p. 32).

Globalization is not a specific object, instead, it is a process. Or more precisely, globalization is a set of accumulating process, resulting from and generating a dialectical whole of political, economic technological, and cultural changes. I define globalization as a multidimensional phenomenon that embodies a shift in organization of human activity and the deployment of power from a local and national orientation towards global patterns, a rising interconnectedness on a global sphere, and a rising awareness of this interconnectedness (PIERIK, 2004, p. 454/455).

Com isso, percebe-se que, a globalização tem claramente encolhido as distâncias e aproximado as pessoas.

Não existe uma definição única e universalmente aceita para a globalização. Como acontece com todos os conceitos nucleares das ciências sociais, seu sentido exato é contestável. A globalização tem sido diversamente concebida como ação à distância (quando os atos dos agentes sociais de um lugar podem ter consequências significativas para "terceiros distantes"); como compressão espaço-temporal (numa referência ao modo como a comunicação eletrônica instantânea vem desgastando as limitaçôes da distância e do tempo na organização e na interação sociais); como interdependência acelerada (entendida como a intensificação do entrelaçamento entre economias e sociedades nacionais, de tal modo que os acontecimentos de um país tem um impacto direito em outros); como um mundo em processo de encolhimento (erosão das fronteiras e das barreiras geográficas à atividade socioeconômica); e, entre outros conceitos, como integração global, reordenação das relaçôes de poder inter-regionais, consciência da situação global e intensificação da interligação inter-regional (HELD; McGREW, 2001, p. 11).

Por conta disso, a globalização abre espaço para a solução dos problemas com base na governança global, uma vez que defende a participação dos atores interessados naquele determinado conflito, em nome de uma coexistência social harmoniosa.

Dessa forma, para a prática da "boa governança”, é necessário o reconhecimento de que problemas comuns exigem açóes conjuntas, além da participação dos Estados, por meio da chamada "participação ampliada", ou seja, atores não estatais, que podem ser definidos como todos os agentes que não pertencem a estrutura estatal, mas atuam num determinado plano (seja nacional ou internacional), produzindo seus efeitos e, consequentemente, gerando influência. Não é um processo, portanto, que exclui a participação dos Estados, mas sim que implica na participação dos mais variados agentes, pois permite a existência e influência de uma infinidade de atores, que contam com suas próprias estruturas e processos de decisão, o que é corroborado por uma das conclusões do relatório da 
Comissão sobre Governança Global: "uma enorme variedade de atores pode estar envolvida em qualquer área da governança” (COMISSÃO SOBRE GOVERNANÇA GLOBAL, 1996, p. 3).

\begin{abstract}
Governança diz respeito não só a instituiçôes e regimes formais autorizados a impor obediência, mas também a acordos informais que atendem aos interesses de pessoas e instituiçóes (...). No plano global, a governança foi vista primeiramente como conjunto de relaçōes intergovernamentais, mas agora deve ser entendida de forma mais ampla, envolvendo organizaçóes não governamentais (ONG), movimentos civis, empresas multinacionais e mercados de capital globais. Com estes interagem os meios de comunicação de massa, que exercem hoje enorme influencia (BIERMANN; PATTBERG, 2012, 281).
\end{abstract}

Em suma, "governança é um fenômeno mais amplo do que governo; abrange as instituiçôes governamentais, mas implica também em mecanismos informais, de caráter não-governamental' (ROSENAU, 2000, p. 15/16).

Neste contexto, a informação exerce papel fundamental, uma vez que a sociedade torna-se dependente de informaçóes, que produziráo efeitos em tempo real, tanto no aspecto global como local. O mundo vai tornando-se, aos poucos, uma grande "aldeia global”.

"Quando o sistema social mundial póe-se em movimento, modernizando-se, vai-se transformando num espécie de aldeia global. De repente, tudo se articula em um vasto e complexo todo moderno, modernizante e modernizado" (GUERRA, 2013, p. 454).

Este fenômeno de intensificação das relaçóes em escala mundial é ampliado pela atuação dos veículos de comunicação de massa, principalmente nas últimas décadas com o advento da internet e das ferramentas de redes sociais, que conectaram localidades distantes de tal maneira ao ponto de acontecimentos locais modelarem eventos ocorridos a milhares de distâncias, "estabelecendo uma globalidade das ideias, padróes e valores socioculturais inimaginários" (IANNI, 1995, p. 93), rompendo as fronteiras nacionais e influenciando culturas, regimes políticos e econômicos, entre outros fatores, e, por consequência, reorganizando a sociedade.

A informação passa então a ser o instrumento de conexão deste novo mundo reestruturado com bases na globalização. Com o advento de que, se de qualidade, esta informação tem o potencial de educar a população, inclusive no que se refere a edificação de uma sociedade sustentável, pois, ao influenciar a opinião pública, acaba por determinar os novos rumos do século XXI.

"Faz-se necessária a difusão de educação capaz de auxiliar na construção do desenvolvimento sustentável, desenvolvimento esse que se dará de forma solidária com o apoio e organizaçâo da sociedade como um todo" (GALLI, 2001, p. 178/179). 
Dessa forma, o atual desafio da sustentabilidade ambiental requer uma melhor aplicabilidade de recursos naturais existentes, para garantir ao longo do tempo a interação entre homem e natureza de forma adequada.

As bases dessa nova interação devem estar fundadas na conscientização e na educação da população em relação ao meio ambiente, o que se faz, primordialmente, por meio da informação, que criará condições para que o cidadão se habilite, de maneira adequada, a defender o meio ambiente.

"De nada sirve establecer cauces de participación si la población no cuenta con la información necesaria para formar su propia opinión” (FERRER, 2013, p. 357).

Isso ocorre, porque, os cidadãos com acesso à informaçáo de qualidade têm melhores condiçóes de articular desejos e ideias e, principalmente, de tomar parte nas decisóes que lhes dizem respeito diretamente, inclusive no que se refere a direitos indisponíveis, como, por exemplo, o meio ambiente, vez que quando se oferece uma quantidade de informação com qualidade (ou seja, estratégica e relevante para o engajamento ambiental), interfere-se na forma e na intensidade com que a população participará da vida social e política.

A qualidade e a quantidade de informação irão traduzir o tipo e a intensidade da participação na vida social e política. Quem estiver mal informado nem por isso estará impedido de participar, mas a qualidade de sua participação será prejudicada. A ignorância gera apatia ou inércia dos que teriam legitimidade para participar (MACHADO, 2006, p. 34).

O direito a informação torna-se, portanto, essencial à participação social no debate e nas deliberaçóes sobre assuntos de interesse público, uma vez que a informaçáo conduz a atuação e participação da sociedade.

A sociedade civil educada com enfoque ambiental terá visão ecossistêmica da ordem pública jurídica e social e poderá assumir um papel mais participativo no controle da comunidade e do Estado, já que estará melhor qualificada para conseguir provocar a ação socioambiental mais efetiva da Administração Pública (COSTA, 2002, p. 447).

De posse da informaçáo, depois de formada a conscientização ambiental, o ser humano é resgatado da passividade, conquista sua cidadania e pode se envolver ativamente na condução de processos decisórios.

O tema do direito à informação tem uma interface necessária com o direito de o indivíduo ser conscientizado da relevância dos temas relacionados à proteção do meio ambiente e, enfim, como o direito subjetivo de participar das decisóes político-administrativas do Estado sob o qual se encontra jurisdicionado (SOARES, 2003, p. 611). 
Dessa forma, a informação ambiental é imprescindível para o efetivo exercício do direito (e também do dever) de participar, bem com essencial para avançar no caminho do desenvolvimento sustentável (conforme proposto pela Agenda 21).

"El aumento progresivo del acceso público a la información, la participación y la justicia, produce decisiones más efectivas, justas y legitimas en cuanto a politicas y proyectos, y forma parte de las garantías para transitar hacia el desarrollo sustentable" (GONZALÉZ, 2007, p. 416).

\section{Conclusões}

A verdadeira missão da imprensa, mais do que a de informar e de divulgar fatos, é a de difundir conhecimentos, disseminar a cultura, iluminar as consciências, canalizar as aspiraçóes e os anseios populares, enfim, orientar a opinião pública no sentido do bem e da verdade (MIRANDA, 1994, p. 51).

É certo que a mídia tem o poder (e a facilidade) de construir a opinião pública. Por esta razão, é função da imprensa não apenas obter e divulgar informaçóes, como também contribuir para a formação de educação e conhecimento, inclusive no que se refere a defesa e proteção do meio ambiente, tendo em vista que grande parte da população somente tem acesso ao conteúdo das informaçóes por meio destes veículos.

Esta situação é intensificada na atual sociedade, em decorrência dos processos de globalização, onde as fronteiras e barreiras geográficas encolheram, aproximando as pessoas e entrelaçando-as, tanto a nível nacional quanto internacional, o que intensifica as consequências sociais significativas da comunicação social.

O encolhimento geográfico e a aproximação de necessidades sociais dos mais diversos lugares e distâncias têm influência direta nos processos de governança, uma vez que, para haja participação efetiva da sociedade no que diz respeito as políticas públicas de meio ambiente, a população deve estar, primeiramente, informada a respeito.

Por isso, o jornalista deve se conscientizar que faz parte de uma das profissôes que exigem maior responsabilidade social, tendo em vista que é um dos watchdogs (guardióes) da sociedade e, é claro, da liberdade de expressão e de imprensa.

Neste sentido, a informação torna-se um instrumento indispensável para a consciência da sociedade quanto a proteção do atual patrimônio ambiental disponível, bem como essencial para a edificação de uma sociedade baseada no desenvolvimento sustentável.

\section{Referências}

ARAUJO, Margarete Panerai; ROSSI, Alberto de Souza. A comunicação social e o desenvolvimento sustentável: caminhos da representatividade. In Revista Conexáo Comunicaçáo e Cultura. v. 7. n. 13. Caixas do Sul: UCS, janeiro/julho de 2008. 
BAHIA, Juarez. Jornalismo, Informação, Comunicação. São Paulo: Livraria Martins Editora, 1964.

BASTOS, Celso Ribeiro; MARTINS, Ives Gandra. Comentários à Constituiçáo do Brasil: promulgada em 05.10.1988 - volume 2. São Paulo: Saraiva, 1988.

BIERMAN, F; PATTBERG, P. Global Environmental Governance Reconsidered. Cambridge/London: The MIT Press, 2012.

CARVALHO, Luiz G.G.C. Liberdade de informação e o direito difuso à informação verdadeira. 2ed. Rio de Janeiro: Renovar, 2003.

CASTELLS, Manuel. A sociedade em rede. 7ed. São Paulo: Paz e Terra, 2003.

CODONHO, Maria Leonor Paes Cavalcanti Ferreira. Desafios para a concretizaçáo da agricultura sustentável no Brasil: uma contribuição do direito para a regulaçáo do uso dos agrotóxicos. São Paulo: Inst. O Direito por um Planeta Verde, 2014.

COMISSÃO MUNDIAL SOBRE MEIO AMBIENTE E DESENVOLVIMENTO. Nosso futuro comum. 2ed. Rio de Janeiro: Editora Getúlio Vargas, 1991.

COMISSÃO SOBRE GOVERNANÇA GLOBAL. Nossa Comunidade Global - Relatório da Comissão sobre Governança Global. Rio de Janeiro: Editora FGV, 1996.

COSTA, José Kalil de Oliveira e. Educação Ambiental, um direito social fundamental. In BENJAMIN, Antonio Herman (Org.). Anais do $6^{\circ}$ Congresso Internacional de Direito Ambiental. São Paulo: Instituto O Direito por um Planeta Verde/ Imprensa Oficial, 2002.

DEFLEUR, Melvin Lawrence. Teorias da Comunicaçáo de Massa. 5ed. Tradução Octavio Alves Velho. Rio de Janeiro: Jorge Zahar Ed., 1993.

FERRER, Gabriel Real. La construción del Derecho Ambiental. In Revista Eletrônica Novos Estudos Jurídicos. Vol. 18, n. 3, pp. 347-368. Santa Catarina: set-dez 2013, p. 357. Disponível em: <www.univali.br/periodicos>.

GALLI, Alessandra. Educação Ambiental como instrumento para o desenvolvimento sustentável. 2ed. Curitiba: Juruá, 2011.

GODOY, Claudio Luiz Bueno de. A liberdade de Imprensa e os direitos da personalidade. São Paulo: Atlas, 2001.

GONZALÉZ, Liliana A. Mendoza. Acceso a la justicia ambiental. In BENJAMIN, Antonio Herman; LECEY, Eladio; CAPPELLI, Sílvia (orgs.). $\mathbf{1 2}^{\circ}$ Congresso Internacional de Direito Ambiental - Meio ambiente e acesso à justiça: flora, reserva legal e APP. Volume 2. São Paulo: Imprensa Oficial do Estado de São Paulo, 2007.

GUERRA, Sidney. A liberdade de imprensa e o direito à imagem. 2ed. Rio de Janeiro: Renovar, 2004. 
. Curso de Direito Internacional Público. 7ed. São Paulo: Saraiva, 2013.

GONÇALVES, Alcindo. Governança Global e o Direito Internacional Público. In JUBILUT, Liliana Lyra (coord.). Direito Internacional Atual. Rio de Janeiro: Ellsevier, 2014.

HELD, David; McGREW, Anthony. Prós e Contras da Globalizaçáo. Rio de Janeiro: Zahar, 2001.

IANNI, Octavio. Teorias da Globalização. Rio de Janeiro: Civilização Brasileira, 1995.

KOVACH, Bill; ROSENSTIEL, Tom. Os elementos do jornalismo. Tradução de Wladir Dupont. São Paulo: Geração editorial, 2003.

MACHADO, Paulo Affonso Leme. Direito à informaçáo e Meio Ambiente. São Paulo: Malheiros, 2006.

MIRANDA, Darcy Arruda. Comentários a Lei de Imprensa. 2ed. São Paulo: Editora Revista dos Tribunais, 1994.

PIERIK, Roland. Globalization and Global Governance: A Conceptual Analysis. In HEERE, W. P. Heere (org.). Government to Governance: The Growing Impact of Non-State Actors on the International and European Legal System. Cambridge: Cambridge University Press, 2004.

RODRIGUES, Marcelo Abelha. Instituiçóes de Direito Ambiental - volume 1. São Paulo: Max Limonad, 2002.

ROSENAU, James N. Governança, Ordem e Transformação na Política Mundial. In ROSENAU, James N; CZEMPIEL, Ernst-Otto. Governança sem governo: ordem e transformação na política mundial. Brasília: Ed. UnB: São Paulo: Imprensa Oficial do Estado de Sáo Paulo, 2000.

SANTOS, Boaventura de Sousa. Globalizaçáo: Fatalidade ou utopia. 3ed. Porto: Afrontamento, 2005.

SILVA, José Afonso da. Curso de Direito Constitucional Positivo. 5ed. São Paulo: Editora Revista dos Tribunais, 1989.

SILVA, Juremir Machado da. O pensamento contemporâneo francês sobre a comunicação. In HOHLFELDT, Antonio; MARTINO, Luiz C.; FRANÇA, Vera Veiga (Org.). Teorias da comunicação: conceitos, escolas e tendências. Petrópolis: Vozes, 2001.

SOARES, Guido Fernando Silva. Direito Internacional do Meio Ambiente: emergência, obrigaçóes e responsabilidade. 2ed. São Paulo: Atlas, 2003.

THOPMSON, John B. A mídia e a modernidade: uma teoria social da mídia. Tradução de Wagner de Oliveira Brandão. Petrópolis: Vozes, 1998. 